\title{
Research on the Reduction of Greenhouse Gases Emissions to the Enrichment in Carbon of the Iron Powders
} \author{
Cristian Ghermec ${ }^{1, a^{*}}$, Mariana Ciobanu ${ }^{1, b}$ and lonela Bucse ${ }^{1, c}$ \\ ${ }^{1}$ University of Craiova, Faculty of Mechanics, Department of Engineering and Management of \\ Technological Systems, $1^{\text {st }}$ Calugareni street, 220037, Drobeta Turnu Severin, Romania \\ acristian_ghermec@yahoo.com, bmaryana_ciobanu@yahoo.com, ${ }^{\mathrm{c}}$ bucse_ionela@yahoo.com
}

Keywords: greenhouse gases, ecological steel, carburizing

\begin{abstract}
The steels elaborated through proceedings that are specific to powder metallurgy have as raw material the iron powder which is enriched in carbon through various proceedings: carburizing in a methane-bearing atmosphere or in a liquefied petroleum gas (LPG)-bearing atmosphere, with the addition of synthetic cementite. In order to be developed as environment friendly technologies, there are made researches in order to reduce GHG emissions.
\end{abstract}

\section{Introduction}

Powder metallurgy is a summation of innovative processes aimed at obtaining advanced materials or improved properties compared to those obtained by conventional methods. As statistics show, the development perspectives of production of parts elaborated through powder metallurgy processes are positive even during the economic crisis. Global sales of PM components are expected to grow from $\$ 23$ billion in 2007 to $\$ 30$ billion by 2012 with an average annual growth rate of $5 \%[1]$.

In the National Romanian Strategy regarding Climatic Changes 2013 - 2020, one of the strategic objectives which must be realized until 2020 is represented by the reduction of the greenhouse gases emissions with $20 \%$ as compared with the year 1990 . The research aims to identify the most effective measures for reducing Greenhouse Gases (GHG) emissions by analyzing and quantifying emissions and removals of GHG for different types of steels obtained through specific proceedings to powder metallurgy. In this context, the research of The Advanced Engineering Group of the Department of Engineering and Management of the Technological Systems, Drobeta Turnu Severin, within the University of Craiova - Faculty of Mechanics has as objective the attainment of ecological steels. The research is part of an ample action whose purpose is the reduction of the greenhouse gases emissions in the academic laboratories [1] and then the extrapolation of the results at the level of producing parts through proceedings that are specific to power metallurgy.

The first step was the analysis of the life cycle of the parts obtained through the carburizing of iron powder in a methane-bearing atmosphere. There were highlighted the advantages of this proceeding: the raw material is represented by the iron powder, wastewater which might need purification or recycling do not result; the final product is a part which does not need afterward processing with solid waste result and therefore the specific energy consume is lower [2]. This is why the steel obtained through this proceeding can be considered ecological steel. The next phase was improving the environmental performances of iron powders carburizing process in a methanebearing atmosphere. The conclusions of this research were as following: the decrease in raw materials and energy consumptions and also the interest in the life cycle of the ecologic steels lead to an increase in the environmental performances of the PM process [3].

\section{Materials and experimental procedure}

Obtaining ecological steels by enrichment in carbon of iron powder must meet these requirements through several research directions:

a) Enrichment in carbon of the iron powders using methane gas or LPG. 
The methane gas and LPG are decomposed, in the absence of oxygen, at temperatures above $900^{\circ} \mathrm{C}$ into carbon and hydrogen, which are not in the category of GHG emissions. The carbon diffuses into the mass of iron powder resulting environment-friendly steel versus conventional steels.

Carburizing in a methane-bearing atmosphere can be realized in three ways: carburizing at the same time with sintering in a total time of electric energy consumption of $780 \mathrm{~min}$ (I) [2], carburizing-sintering with the application of a debinding bearing at $350^{\circ} \mathrm{C}$ and with time of electric energy consumption of $415 \mathrm{~min}$ (II) [4] and sintering followed by carburizing for 370 minutes (III) [3]. The carburizing temperature is of $910^{\circ} \mathrm{C}$ and the sintering temperature is of $1150^{\circ} \mathrm{C}$. The sintering takes place under an atmosphere of argon. The carburizing and sintering phases take place in a thermo resistant oven (fig.1).

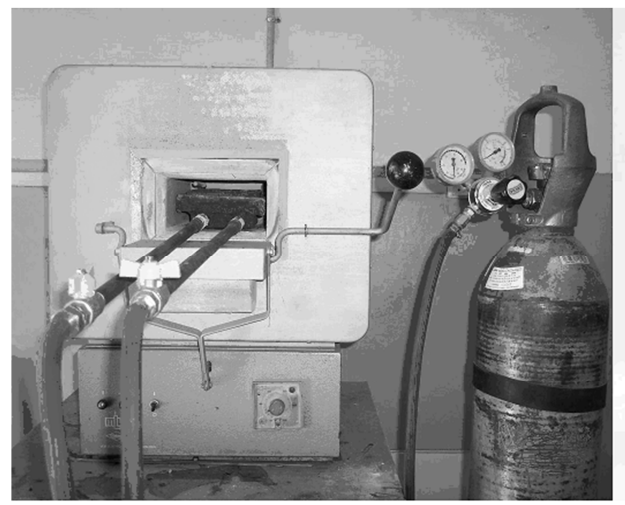

a

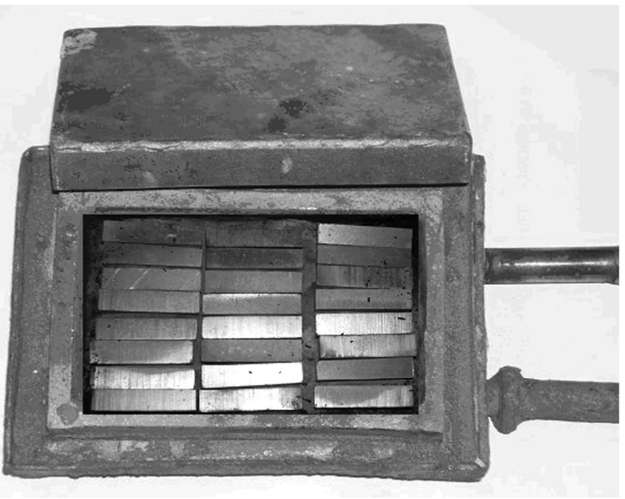

b

Fig.1 The installation of carburizing-sintering:

$\mathrm{a}$ - the thermo resistant oven; $\mathrm{b}$ - the carburizing - sintering box

In this research, at a carburizing sintering cycle there were realized 72 rectangular parts with the dimensions of $50 \times 10 \times 10 \mathrm{~mm}$.

Synthetic cementite was prepared by overcarburizing the iron powder in a methane bearingatmosphere [5]. The use of methane has the same advantages as the previously analyzed case. Since graphite has a negative impact on the environment and human health, its replacement in powder metallurgy processes results in the greening of the products obtained.

\section{Results and discussions}

According to EN ISO 14064-1:2012, when obtaining ecological steels, there are two types of emission: indirect emissions of GHG and other indirect emissions of GHG [6]. The research has followed indirect emissions of GHG because they have the biggest share in the total emissions.

a) Enrichment in carbon by carburizing in a methane or in a LPG bearing- atmosphere.

Methane is found under the form of natural deposists in an almost pure state, in Romania the purity of methane being of $99 \%$, which makes possible its usage in the process of carburizing of iron powders. There are technologies for the production of methane gas from bio methane which reduces GHG by reusing agricultural waste.

LPG results as a byproduct of oil refineries and contains at least $90 \%$ fraction $\mathrm{C} 4$ and up to $9 \%$ fraction C3 which makes it suitable to be used in the production of ecological steel. GPL is delivered in recipients under pressure, in liquefied state. In the conditions of Romania, the network of supply with methane gas is not extended on its entire territory and this is why the application of the proceeding is limited. By developing the proceeding of carbon enrichment in a GPL atmosphere it is created the possibility of producing parts through powder metallurgy in the areas that are not connected to the methane gas network. If the demand for certain parts is sufficiently high, it can be 
founded a production workshop in the nearby of the used. This way, the GHG emissions due to the transport of the parts are reduced. Any environmental effect caused by LPG is not known to exist.

Indirect emissions of GHG for carburzing-sintering come from imported electricity. The evaluation of GHG emissions is made through calculus (the product between the consumption of energy and the emission factor). National LCA emission factor for consumed electricity $\left(\mathrm{tCO}_{2}-\right.$ eq/MWhe) for Romania is 1.084 as compared to the European average of 0,578 [7].

In order to reduce the greenhouse gases emissions, actions were taken through the modification of the degree of heating and the reduction in the carburizing-sintering time [3].

The reduction in the carburizing-sintering time leads to a decrease in the cosumption of electric energy, as shown in figure 2.

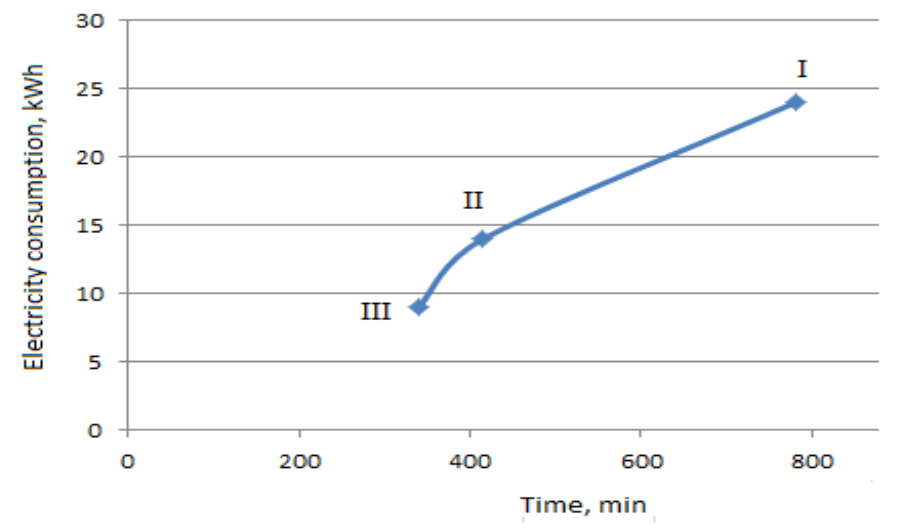

Fig.2 Reducing electricity consumption in carburizing in methane-bearing atmosphere I - carburizing - sintering for $780 \mathrm{~min}$; II - carburizing - sintering for $415 \mathrm{~min}$; III - sintering - carburizing for $370 \mathrm{~min}$

It can be seen that passing from version I to version II brings about a decrease in the consumption of electric energy of $43.5 \%$; the reduction is accentuated with another $30.7 \%$ by applying the third proceeding. The evolution of GHG emissions is proportional with that of electricity consumption.

b) Enrichment in carbon of the iron powders using synthetic cementite

Graphite, natural or synthetic, is consumed in large quantities in powder metallurgy and is the basic raw material used for enrichment in carbon of the iron powder in order to obtain sintered steels. The properties of the parts depend on the purity of graphite; an amount of under $0.03 \%$ of silicon dioxide reduces the diffusion of carbon in iron. This is why, in order to realize parts with high mechanical properties, it is necessary to have pure graphite; even a low number of foreign particles lead to a decrease in the mechanic resistance of the steel [8]. Purification technologies of natural graphite are consuming energy and the raw material for synthetic graphite is oil.

Synthetic cementite prepared by over carburizing of iron powder in a methane-bearing atmosphere replaces graphite in the process of carbon enrichment of the iron powders. The advantage is represented by the elimination of the phase of reducing $\mathrm{Fe}_{2} \mathrm{O}_{3}$ in a $\mathrm{H}_{2}$ medium. The innovative process of enrichment in carbon steels with synthetic cementite eliminates emissions of GHG that are specific to manufacturing of pure graphite and hydrogen.

c) The parts realized through proceedings that are specific to powder metallurgy from the steels obtained through the analyzed proceedings can have complex shapes obtained only through pressing in adequate moulds. The moulds are realized through computer aided design so that it is produced the maximum number of parts at a single carburizing-sintering. There are eliminated manufacturing proceedings that consume a lot of energy such as casting, forging or lamination. The losses in material when pouring the powders in the mould are insignificant. The parts of steels obtained through enrichment in carbon by carburizing in methane or in a LPG-bearing atmosphere or through enrichment in carbon of the iron powders using synthetic cementite are $100 \%$ recyclable. 
d) It was continuously improved the life cycle of the products obtained through the analyzed proceedings. An assessment criterium is reprezented by the wear behaviour of the parts which was established using the tribometer (fig.3).
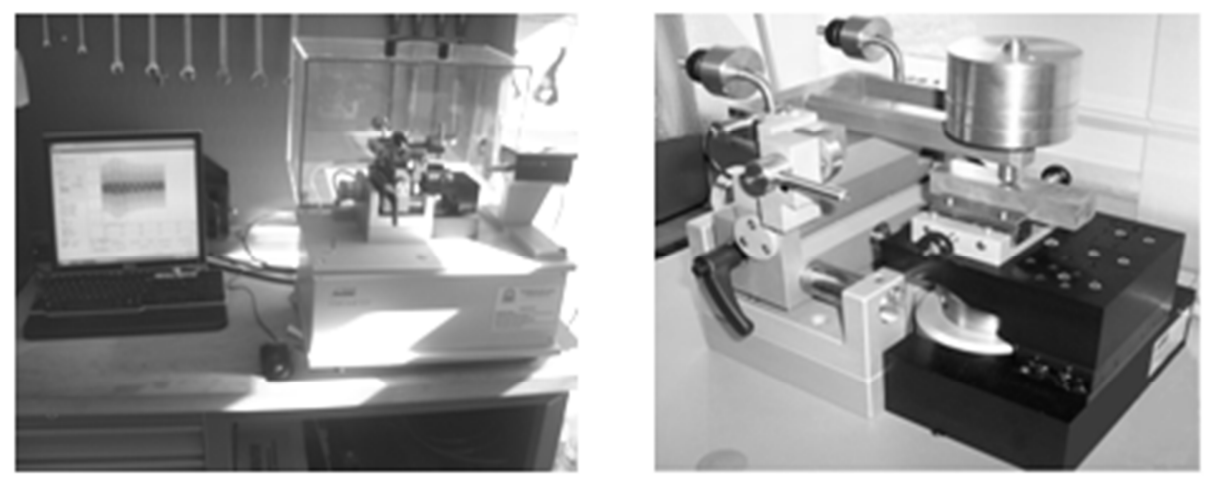

Fig.3 Tribometer type TRN $01-02541$

For the parts of steel obtained by carburizing in a methane-bearing atmosphere, the friction coefficient evoluated between 0,225 and 0,828 and stabilized at the value $\mu=0,77$ which is in the domain of the steel-on-steel friction couples (fig. 4).

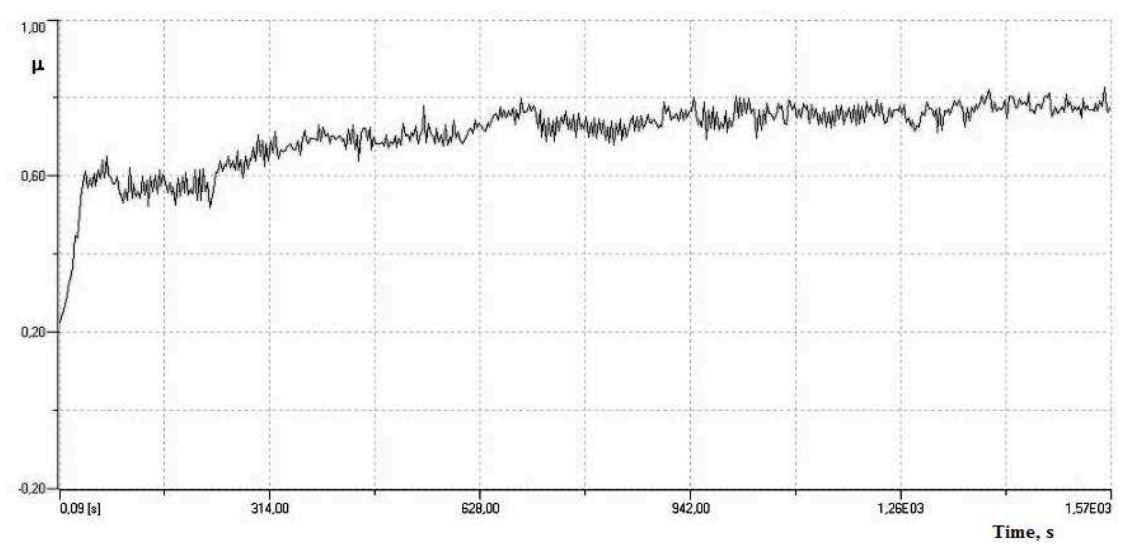

Fig.4 The evolution of the friction coefficient for the parts of steel obtained by carburizing in a methane-bearing atmosphere

In fig. 5 it is shown the evolution of the friction coefficient for the parts where the enrichment in carbon of the iron powders was made using synthetic cementite.

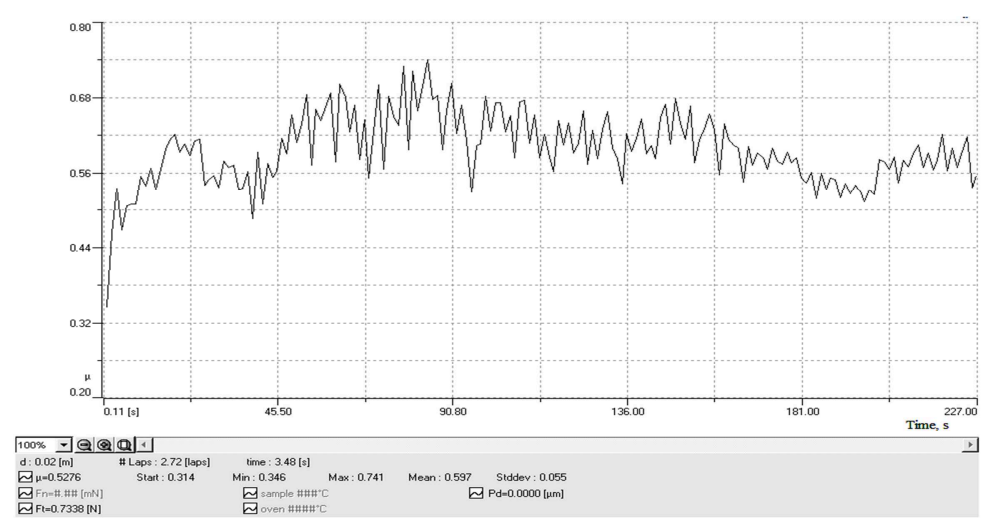

Fig.5 The evolution of the friction coefficient for the parts of steel obtained by enrichment in carbon of the iron powders using synthetic cementite 
The friction coefficient varied between the minumum value $\mu=0,346$ and the maximum value $\mu$ $=0,741$ and stabilized at the final value $\mu=0,597$ which is in the steel-on-steel friction domain.

\section{Conclusions}

Innovative processes of enrichment in carbon of the iron powders in order to obtain ecological steels do not affect their quality, but reduce in a significant proportion the GHG emissions. Therefore these can be considered sustainable technologies.

Properties of parts obtained by the enrichment in carbon of the iron powders by carburizing or by addition of synthetic cementite fall in value in the requirements for sintered steels. It is to be remarked the good wear behavior of both steels which improves the life cycle of these products.

These processes allow the reduction of the GHG emissions through the best techniques applicable to products elaborated through the same proceeding and establish the most efficient proceedings resulted from the comparative analysis of the GHG emissions.

\section{References}

[1] O., Ghermec, C, Ghermec, Research regarding the reduction of the greenhouse gases emissions in the academic laboratories; case studies, Ecoterra - Journal of Environmental Research and Protection, (2013), no. 37, p.61-65, ISSN:2248-3128, Cluj-Napoca, Romania.

[2] O.,Ghermec, C., Ghermec, T., Popescu - A new technology to obtain ecological steels, Environmental Engineering and Management Journal, September/October (2009), Vol.8, No.5, p. 1141-1144, ISSN: 1582 - 9596.

[3] O., Ghermec, C., Ghermec, S., Dubovan, C. O., Rusănescu, Improving the environmental performances of iron powders carburizing process in a methane-bearing atmosphere, Environmental Engineering and Management Journal, October (2013), Vol.12, No. 10, p. 2019-2023, ISSN: 1582 9596, Iasi, Romania.

[4] J. Ghercioiu, Research on elaboration of hybrid sintered steels with applications in manufacturing wear resistant parts, $\mathrm{PhD}$ Thesis, University of Craiova, Romania, (2011)

[5] M., Ciobanu, I., Bucse, C., Nicolicescu, C., Ghermec, S., Radu, The production of sintered carbon steels as mixture of powders of iron and cementite, EURO PM2007 Congress, Toulouse, France, (2007), Vol. II, p. 275.

[6] EN ISO 14064-1:2012 Greenhouse gases-Part 1: Specification with guidance at the organization level for quantification and reporting of greenhouse gas emissions and removals.

[7] http://www.eumayors.eu/IMG/pdf/technical_annex_en.pdf.

[8] C. Ghermec, Studies on the processes of carburizing of iron powders, PhD Thesis, University of Craiova, Romania, (2008). 